\title{
An approach to the modelling of stability of waste containers during urban flooding
}

\section{Eduardo Martínez-Gomariz $^{1,2}$ (c) ｜ Beniamino Russo ${ }^{3,4}$ | Manuel Gómez ${ }^{1,2}$ | Aurea Plumed $^{5}$}

\author{
${ }^{1}$ CETaqua Water Technology Centre \\ Environment, Society and Economics Area, \\ Cornellà de Llobregat, Spain \\ ${ }^{2}$ Civil and Environmental Engineering \\ Department (DECA), Flumen Research \\ Institute, Technical University of Catalonia, \\ Barcelona, Spain \\ ${ }^{3}$ AQUATEC (SUEZ Advanced Solutions), \\ Barcelona, Spain \\ ${ }^{4}$ Group of Hydraulic and Environmental \\ Engineering, Technical College of La \\ Almunia (EUPLA), University of Zaragoza, \\ Spain \\ ${ }^{5}$ Operational Management Department, \\ Barcelona City Council, Cleaning and Waste \\ Management Facilities Direction, Barcelona, \\ Spain

\section{Correspondence} \\ Eduardo Martínez-Gomariz, Cetaqua Water \\ Technology Centre, Environment, Society \\ and Economics Area, Cornellà del \\ Llobregat, Spain. \\ Email: eduardo.martinez@cetaqua.com \\ Funding information \\ H2020 Environment, Grant/Award Number: \\ 700174
}

\begin{abstract}
Before the solid waste is dumped in landfills, the collection process for large Spanish cities starts from a regular collection of household waste municipal service which is carried out through street containers. When an urban flood occurs those containers may lose their stability, thereby allowing debris (i.e., solid waste contained) and leachate to escape from the container and contaminate the flood water. Moreover, once a container loses its stability it can further constrict a narrow street and increase flooding, thereby creating a closed basin with no outlet for runoff and exacerbating the effects of flooding. Therefore, the waste containers stability when exposed to flooding is definitely an environmental, safety and health concern to be addressed. In this research stability functions for waste containers exposed to urban floods have been derived. These thresholds have been employed to analyse the containers' potential behaviour during floods in Barcelona. In order to validate the model a historical rainfall has been modelled and low-return-period design storms (i.e., 1, 5, and 10 years) have been used to assess the containers vulnerability against floods for frequent rainfall events. Once the number of potentially unstable containers has been estimated, an adaptation measure has been proposed in order to increase the resilience of waste sector against urban floods in Barcelona.
\end{abstract}

\section{K E Y W O R D S}

environment, health, safety, urban floods, waste containers

\section{1 | INTRODUCTION}

Cities around the world can be affected by floods. However, urban floods may have different sources and are called riverine flood, when the main river bed exceeds its capacity; stormwater flood, when the conveyance capacity of the urban drainage system is exceeded; or coastal flood, when the seawater causes the flooding. Only stormwater floods may affect any city, even if neither is a coastal city nor have a nearby river to be overflowed (Patra, Kumar, \& Mani, 2016; Kundzewicz et al., 2014).

Stormwater flooding occurs because the "exceedance flow" is generated on the urban surface. For this reason, the design of drainage systems should consider the dual drainage concept (Djordjevic, Prodnovic, \& Maksimovic, 1999; Nanía, León, \& García, 2015; Russo, Sunyer, Velasco, \& Djordjević, 2015; Schmitt, Thomas, \& Ettrich, 2004), through which certain amount of runoff is assumed to flow on the streets because only a portion of runoff can be conveyed by the sewer system. The term pluvial flooding is sometimes used synonymously with stormwater flooding, or sometimes used to denote urban flooding where there is no sewer network or the network is already at full capacity (Butler \& Davies, 2011). When accepting the dual drainage concept, the consequences of this flow on the streets must be analysed by ensuring firstly a high level of safety for 
pedestrians (Martínez-Gomariz, Gómez, \& Russo, 2016) but also minimising the direct and indirect economic damages. Therefore, a comprehensive flood risk assessment must be conducted in order to implement adaptation measures if necessary.

On the other hand, the action of protecting against and planning responses to a wide range of security challenges that threaten cities and urban areas (i.e., from flooding to terrorism) has been referred to as "urban resilience." Therefore, according to Coaffee and O'Hare (2008)), urban resilience refers to both the design alterations and managerial and governance measures that seek to prevent or mitigate the physical and social vulnerability of areas (i.e., protecting life, properties and economic activities).

Even though, a wide range of urban resilience definitions can be found within the research literature, some authors addressing this concern (Meerow, Newell, \& Stults, 2016) state that the common definition should balance the need to clarify theoretical inconsistencies while retaining requisite flexibility. Moreover, applying resilience in different contexts requires answering: Resilience for whom and to what? When? Where? And why? (Meerow et al., 2016). According to these resilience definitions, when dealing with and proposing adaptation measures for urban floods we are, in fact, acting to improve the urban resilience to flooding or urban flood resilience.

Adaptation measures to improve urban flood resilience span a range of technical subject areas which, apart from hydrological and hydraulic flood studies, should include urban planning and design, urban drainage, building construction and asset management of infrastructure networks (Escarameia, 2016). Furthermore, it should be borne in mind that an urban area has to be considered as an entity composed by different elements and not merely as a set of buildings (Lhomme, Serre, Diab, \& Laganier, 2013). It is acknowledged that it is an interesting and useful exercise to think of a city as a system (Zevenbergen et al., 2010). This system is formed by different sectors (i.e., water, power, mobility, waste, and telecommunications), which, in turn, are comprised of several urban services and infrastructures.

The EU funded RESCCUE project (RESilience to cope with Climate Change in Urban arEas; www.resccue.eu), in which this study is framed, aims at helping cities to become more resilient to physical, but also social and economic challenges by generating models and tools to bring this objective to practice. In a comprehensive urban resilience assessment within RESCCUE project, interdependencies and cascading effects due to failure caused by climate event impacts are taken into account. This assessment is carried out through two different scales approaches: a holistic study (an all-city study by employing the Hazur ${ }^{\circledR}$ platform) (Evans et al., 2018), and specific studies for different urban services affected by a specific climate event, such as municipal solid waste management affected by floods.

Municipal solid waste management and wastewater contribute about $3 \%$ to current global anthropogenic greenhouse gas emissions, about half of which is methane from landfills. One forecast suggests that without mitigation, this could double by 2020 and quadruple by 2050 (UN-HABITAT, 2010). For this reason, most research studies are focused on studying mitigation strategies to deal with greenhouse gas emissions due to landfills. Mitigation needs to be a mix of the "technical fix" approach, such as landfill gas collection and utilisation, and upstream measures, particularly reduction, reuse, recycling and composting. Solid waste management, often a neglected aspect of urban management, is a problem in both developed and developing countries (Sam, 2002) and there are reasons (Lamond, Bhattacharya, \& Bloch, 2012) to consider serious issues in flood risk management: (a) blockages in drainage and watercourses because of a poor disposal of waste, which reduces their conveyance and leads to flooding; (b) debris in floodwaters can cause increased damage to property and increase the economic impacts; (c) deposition of waste, after a flood, can block access and be a source of toxins and breeding ground for disease; and (d) leaching of toxins into groundwater.

Only a few studies focused on the impacts caused by climate change on waste sector (United States Agency for International Development [USAID], 2012, 2014, 2015; Winne et al., 2012; Zimmerman \& Faris, 2010). By assuming more intense rainfall events, potential impacts on solid waste management are described, such as: saturated soils and decreased stability of slopes and landfill linings at waste management sites; increased risk of flooding (fluvial and flash floods) affecting facilities, access and use of mobile plant; increased risk of flood-related disruption to critical infrastructure and suppliers (transport, energy, ICT, etc.).

As stated, the main research effort regarding climate change-related impacts of solid waste sector is focused on offering mitigation measures and strategies in order to reduce the waste greenhouse gases emissions. However, no research studies addressed the reverse problem: how climate change impacts on solid waste sector. Landfills are mainly in the centre of these studies, offering adaptation measures in order to increase the resilience of this sector when impacted by different hazards resulting from climate change (e.g., more frequent urban floods). Nevertheless, before the solid waste is dumped in landfills, the collection process for large Spanish cities starts from a regular collection of household waste municipal service which is carried out through street containers. Therefore, when an urban flood occurs those containers may lose their stability, thereby allowing debris (i.e., solid waste contained) and leachate to escape from the container and contaminate the flood water. Also the container itself may be washed 
away (i.e., a massive debris) together or separately with its content (Figure 1). Such type of massive debris carried by floodwaters, similar to vehicles (Martínez-Gomariz, 2016; Martínez-Gomariz, Gómez, Russo, \& Djordjević, 2018), can further constrict a narrow street and increase flooding, thereby creating a closed basin with no outlet for runoff and exacerbating the effects of flooding. This hazard is greatest upstream of culverts, bridges, or other places where debris can collect. On the other hand, inlets and sewers can become clogged with solid waste if it comes out of the container after it loses stability, thereby worsening the drainage system and contributing to exacerbate the flood impacts. Consequently, the waste containers stability when exposed to flooding is definitely an environmental, safety and health concern to be addressed.

The main cascading effects due to containers' instabilities may be listed as follows:

- Traffic disruption: Traffic may be disrupted not just while flood is occurring but also after the event when these containers that were washed away may be left on roads.

- Waste collection disruption: After a flood event, the waste collection may be disrupted if containers were moved from their original location. The municipal workers have to relocate them and even collect their content in case it came out from the container after losing the stability.
- Potential sewer blockages: Potential fractions coming out from the container may block sewers and thereby adversely affect the drainage efficiency.

- Increased likelihood of cascading effects due to flooding: If containers, moved from their original position, lay at narrow streets or accumulate at inlets, culverts or bridges, water depths may increase and therefore the flood consequences will be aggravated. A flood without important consequences may turn into a flood which cause a cascading effect to other sectors.

The present research focuses on the stability of the containers when exposed to urban floods that Barcelona City Council has distributed across the city to provide waste collection to citizens. A description of how waste and recycling collection is managed in Barcelona together with the description of the types of containers and which kind of fractions they may contain is presented first. Afterwards, a comprehensive study of the forces acting on a flooded container, the different modes of instabilities and the derivation of the formula for the stability threshold (i.e., the velocity and water depth combinations which lead to the containers instability) is conducted. Finally, these obtained stability thresholds are employed to analyse the potential behaviour of containers against floods in Barcelona caused by historical and low-return-period design storms (i.e., 1, 5, and
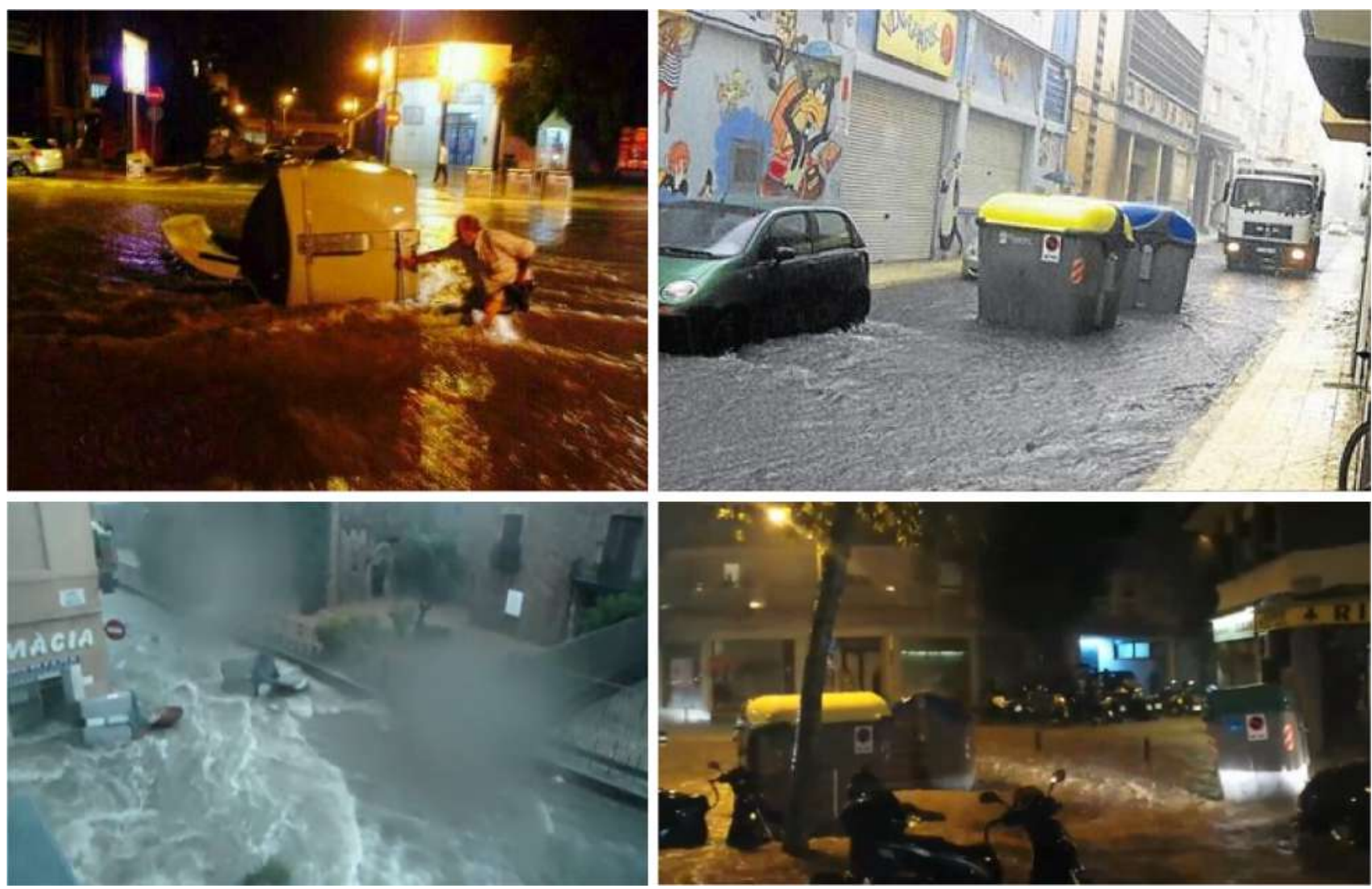

F I G U RE 1 Real containers removed due to flooding in Barcelona 
10 years). Adaptation measures in order to improve the resilience of waste sector against urban floods in Barcelona will be proposed based on the results of the case study of the stability of containers exposed to flooding.

\section{I WASTE AND RECYCLING COLLECTION SERVICE BY CONTAINERS IN BARCELONA}

\section{1 | Description of waste and recycling Barcelona municipal service}

Barcelona has an extensive municipal service for a daily collection of household and commercial waste to provide waste collection to citizens and ensure a clean and healthy public space. This service is carried out through street containers, door to door bags collection service, pneumatic collection boxes and bins for collection in shops. Waste which cannot be placed in conventional containers is delivered to Green Dots. Citizens also have special services regarding waste collection, such as old furniture and clothes, dead animals, debris bags gardening waste, fibrocement or asbestos.

Taking part in the recycling waste collection is the first step in dividing household waste and a civic gesture which contributes to preserving the environment. Waste can be reused by recycling it, so it can become a resource and provide environmental and social benefits for everyone. In the context of public awareness campaigns, Barcelona City Council is promoting actions and tools to accompany the citizens in improving household waste collection through educational activities and training which are addressed at the public and groups from the city.

Barcelona opts for a recycling collection including five different fraction-types of containers. There are containers for each one of them located citywide in order to make waste management easier: waste, organic, paper and cardboard, packaging, and glass. All citizens have recycling collection containers located less than $100 \mathrm{~m}$ from their home.

\section{2 | Type of containers and fractions characterisation}

In Barcelona there are a total of 27,134 containers, which can be classified either according to the fraction they contain (i.e., waste, organic, paper and cardboard, packaging, and glass), their volume in litres (i.e., 3,200; 3,000; 2,400; 2,200 ; and 1,800 ) or the way they are loaded (i.e., lateral, bilateral, rear, underground). The percentage distribution according to their fractions is as follows: $44 \%$ (waste), $22 \%$ (organic), 12\% (paper and cardboard), 11\% (packaging), and $11 \%$ (glass). Regarding their loading their distribution is as follows: $62 \%$ (lateral), 25\% (bilateral), 12\% (rear), and 1\% (underground).

Due to the less percentage of rear and underground loading-type containers when comparing with lateral and bilateral type (Figure 2), only the former have been taken into account in this study, which is an $87 \%$ of the total number of containers. Table 1 and Figure 3 show the distribution of studied containers both per districts and type of fraction.

The positioning of the containers in the city is as follows: these are placed in groups of 4 or 5, one per type of fraction to be collected, and their position on the streets is established either by painting enclosed areas on the ground or by defining their area with plastic yellow pieces, which are used also as guides to place the containers on it (Figure 4). That is the reason for the containers to have a hollow along their base, to place the yellow guides on it. These hollows, as will be explained later, contribute to a better stability against the buoyancy.

In order to analyse the containers stability, an important parameter is their weight, which can vary greatly depending on their filling degree and the type of contained fraction. Moreover, when it comes to different fractions inside the containers the concept of bulk density has to be presented. In contrast to density, bulk density is only used in cases where the particles or chunks of matter are loosely packed with space for air within. Therefore, bulk density is not an intrinsic property of a material, in contrast to density (DifferenceBetween.com, 2011). The following bulk densities $\left(\mathrm{kg} / \mathrm{m}^{3}\right)$ for the different fractions have been proposed, based on the values recommended by the Cogersa-AstUR project (n.d.) and The Spanish Ministry of Agriculture and Fisheries, Food and Environment (MAPAMA, n.d.): (a) waste (113.92); (b) organic (387.5); (c) paper and cardboard (70); (d) glass (330); and (e) packaging (26.5).

(a)

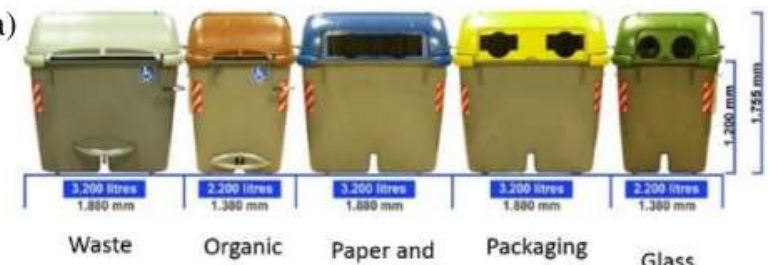

(b)

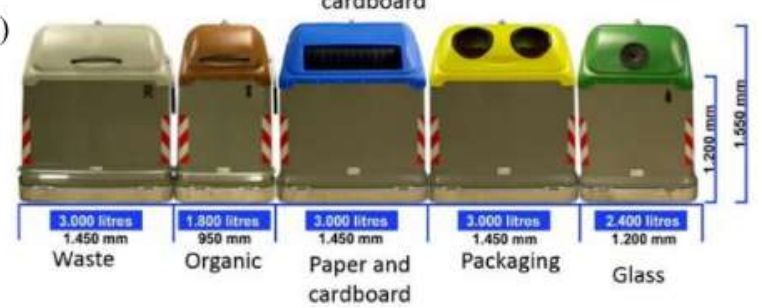

F I G URE 2 Types of containers in Barcelona: (a) lateral load, and (b) bilateral load 
T A B L E 1 Total number of containers in Barcelona and studied ones per districts and type of fraction

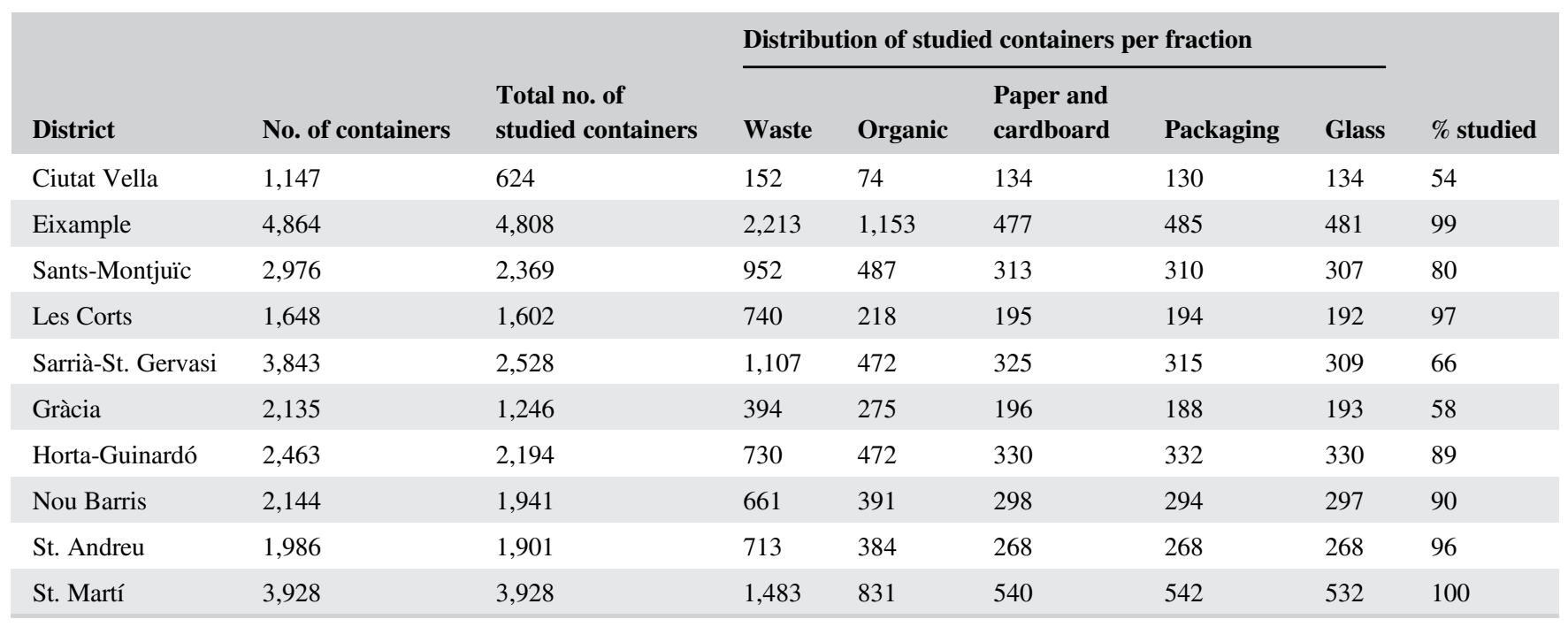
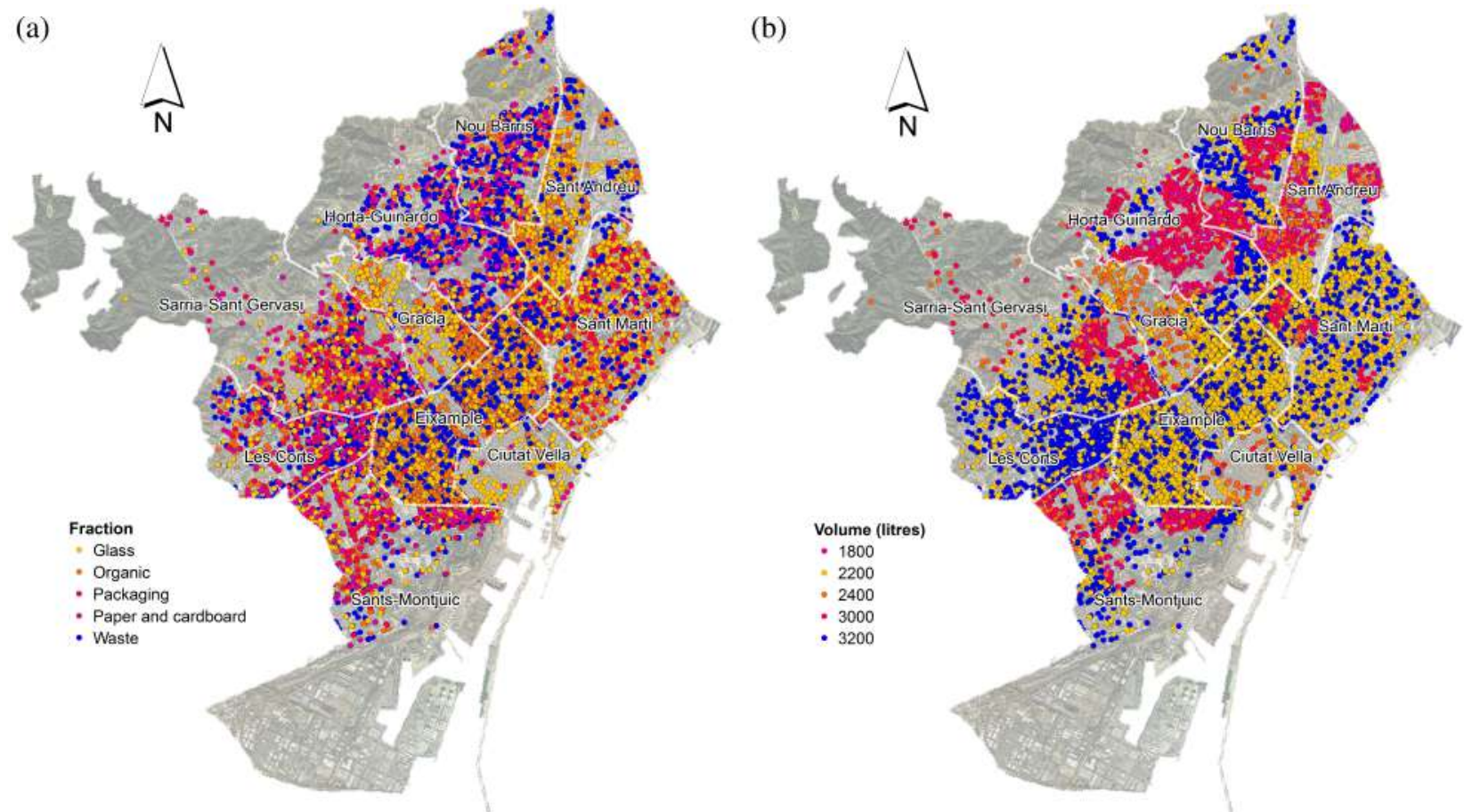

F I G URE 3 Containers distribution in Barcelona classified according to (a) fraction type, and (b) volume. Note: due to the great amount of containers, in some cases a dot indicates a location for a set of even five containers of different fractions/volumes. Therefore, within the map only a type of container, either classified by volume or fraction, is represented for each dot
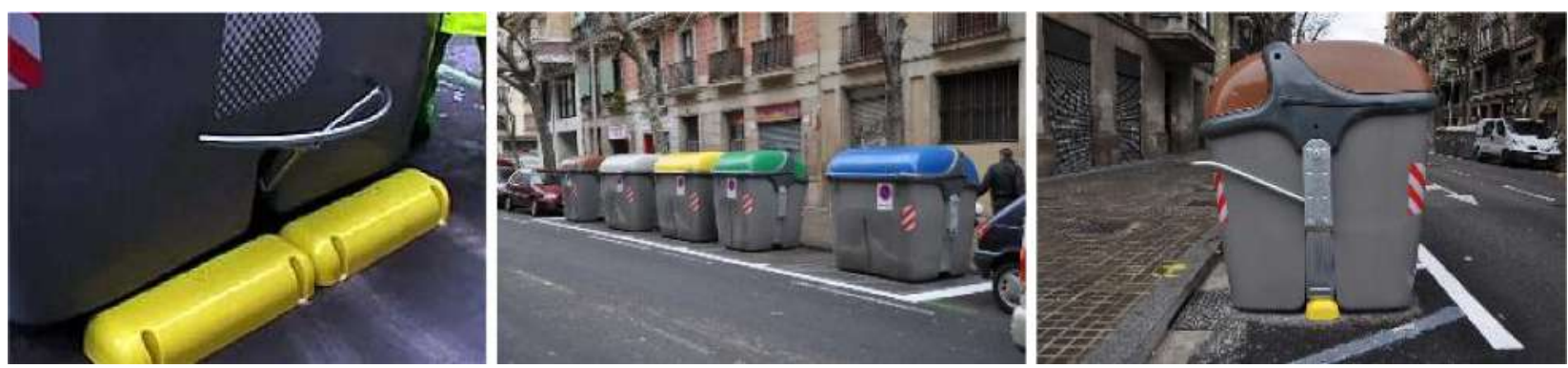

F I G URE 4 Positioning of the containers on the street 
Therefore, the container weight can be defined as a linear function depending on the type of fraction (i.e., the slope of the function) and the filling percentage (1):

$$
W\left(m_{i}, p\right)=W_{o}+m_{i} \times \frac{p}{100},
$$

where $W(\mathrm{~kg})$ is the container total weight, $W_{0}(\mathrm{~kg})$ is the unladen container weight, $m_{i}(\mathrm{~kg})$ is the slope of the function related to each type of fraction, and $p(\%)$ is the percentage value of the filling.

Figure 5 plots, as example, the weight linear functions for a 3,200 L lateral container for the three types of fraction that this container might contain.

In Table 2, all basic characteristics for the considered containers in this study are collected, grouped according to the type of loading, volume and fractions. The considered important parameters are: Ground clearance (GC) (i.e., the distance from the ground to the body of the container), width and depth ( $L_{1}$ and $L_{2}$ respectively), volumes of hollows at the base

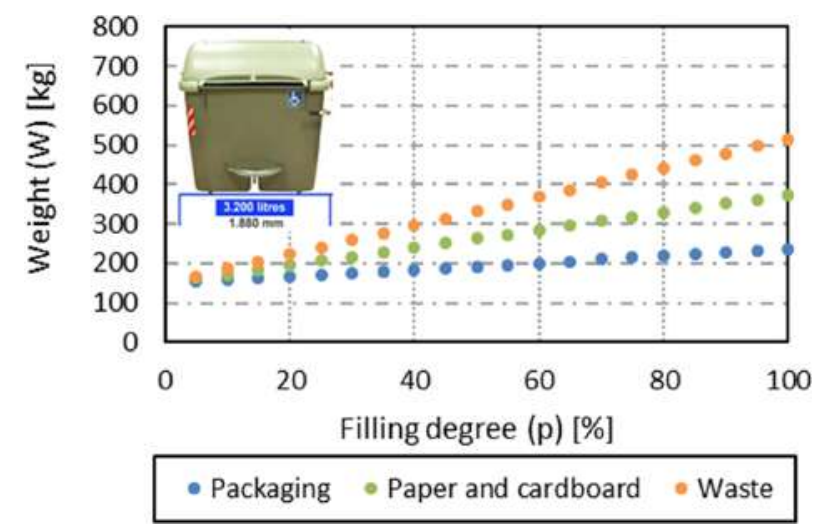

F I G U RE 5 Container's weight functions for a volume of 3,200 L and three different fraction types (packaging, paper and cardboard, and waste) according to its filling degree ( $p[\%])$ of each type of container ( $V_{\text {hollow1 }}$ and $V_{\text {hollow2 }}$ ), unladen weight, and the slope of the weight linear function related to each fraction and container volume (see Figures 7-8).

\section{3 | CONTAINERS STABILITY WHEN EXPOSED TO FLOODING}

\section{1 | Forces and torques acting on a flooded container}

Two types of forces and torques may be considered in order to analyse the stability of such urban elements exposed to flooding, those due to the water flow (i.e., hydrodynamic forces) and those due to the container contact with the ground (Figure 6). Focusing firstly on hydrodynamic forces, drag force $\left(F_{D}\right)$ and vertical pushing force $\left(F_{v}\right)$ are the ones that may affect the container stability. Drag force $\left(F_{D}\right)$ may be expressed as follows:

$$
F_{D}=\frac{1}{2} \rho_{w} v^{2} C_{d} A
$$

where $\rho_{w}$ is the water density, $v$ is the water velocity, $C_{d}$ is the drag coefficient, which depends on Reynolds number and the shape of the container (i.e., rectangular prism), and $A$ is the projected area of the submerged container part perpendicular to the flow direction. The other hydrodynamic force is the vertical pushing force $\left(F_{v}\right)$ which is the combination of the lift force $\left(F_{L}\right)$ and the buoyancy force $\left(F_{b}\right)$ (Martínez-Gomariz, Gómez, Russo, \& Djordjević, 2017). A container is expected to lose its stability for low or zero (i.e., hydrostatic conditions) once the water depth reaches the buoyancy depth, therefore, for simplicity, only buoyancy force, even for hydrodynamic conditions, is considered in this study $\left(F_{v} \approx F_{b}\right)$.

\begin{tabular}{|c|c|c|c|c|c|c|c|c|c|c|}
\hline Load & Volume (L) & Fraction & Units (u) & GC (m) & $L_{1}(\mathbf{m})$ & $L_{2}(\mathbf{m})$ & $V_{\text {hollow1 }}\left(\mathbf{m}^{3}\right)$ & $V_{\text {hollow2 }}\left(\mathbf{m}^{3}\right)$ & Unladen weight $(\mathrm{kg})$ & $m_{i}(\mathrm{~kg})$ \\
\hline Lateral & 3,200 & Packaging & 2,044 & 0.03 & 1.70 & 1.45 & 0.054 & 0.015 & 150 & 0.85 \\
\hline Lateral & 3,200 & Paper and cardboard & 2,041 & 0.03 & 1.70 & 1.45 & 0.054 & 0.015 & 150 & 2.24 \\
\hline Lateral & 3,200 & Waste & 7,033 & 0.03 & 1.70 & 1.45 & 0.054 & 0.015 & 150 & 3.65 \\
\hline Lateral & 2,200 & Organic & 3,684 & 0.03 & 1.20 & 1.45 & 0.038 & 0.015 & 120 & 8.53 \\
\hline Lateral & 2,200 & Glass & 2,034 & 0.03 & 1.20 & 1.45 & 0.038 & 0.015 & 120 & 7.26 \\
\hline Bilateral & 3,000 & Packaging & 1,013 & 0 & 1.45 & 1.60 & 0.026 & - & 295 & 0.80 \\
\hline Bilateral & 3,000 & Paper and cardboard & 1,035 & 0 & 1.45 & 1.60 & 0.026 & - & 295 & 2.10 \\
\hline Bilateral & 3,000 & Waste & 2,112 & 0 & 1.45 & 1.60 & 0.026 & - & 295 & 3.42 \\
\hline Bilateral & 1,800 & Organic & 1,136 & 0 & 0.95 & 1.60 & 0.017 & - & 195 & 6.98 \\
\hline Bilateral & 2,400 & Glass & 1,009 & 0 & 1.10 & 1.60 & 0.022 & - & 250 & 7.92 \\
\hline
\end{tabular}

TA B LE 2 Characteristics of different types of containers in Barcelona 


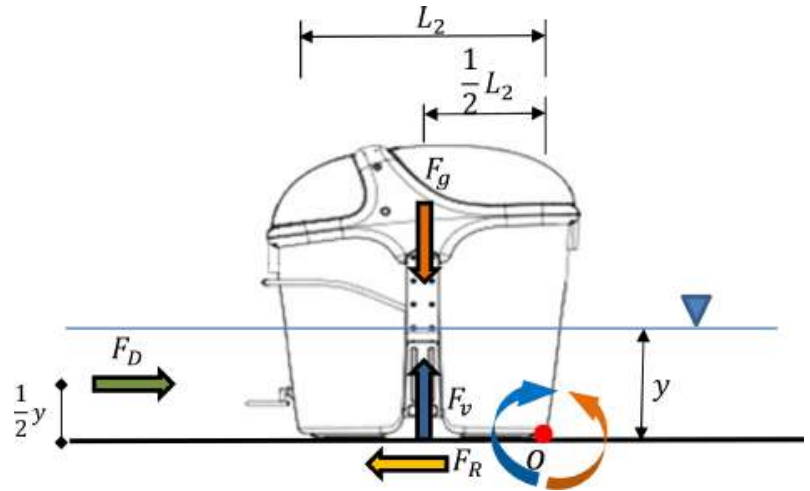

F I G U RE 6 Forces acting on a flooded container (flow direction parallel to L2)
According to Archimedes' principle, the buoyancy force acting on a flooded container is defined as expression (3) indicates:

$$
F_{b}=V_{d i s p} \cdot \gamma_{w} \text { assuming } V_{d i s p} \approx L_{1} \cdot L_{2} \cdot y,
$$

where $V_{\text {disp }}$ is the displaced container volume, $L_{1}$ and $L_{2}$ are the container width and depth respectively, $\gamma_{w}$ is the specific weight of water, and $y$ is the water depth.

Nevertheless, the container is expected to become buoyant for low water depths, thus the contribution of the containers bottom hollows on reducing buoyancy will likely be significant. For this reason, these hollows (Figure 7) have
F I G URE 7 Displaced volume in a flooded container

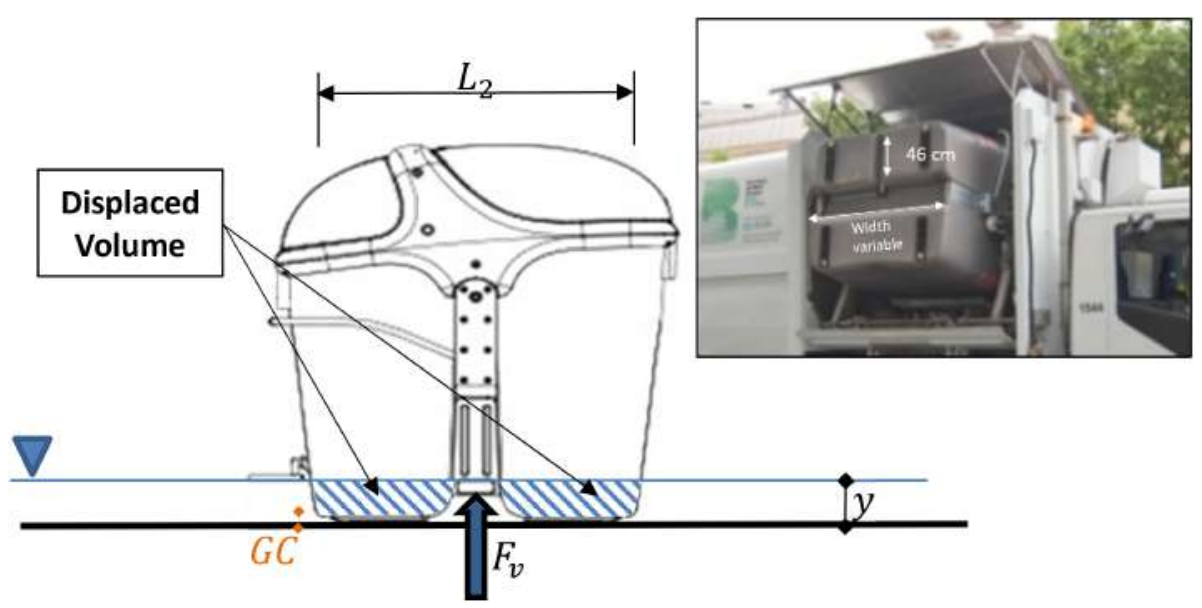

FIG URE 8 Hollows in the containers' base

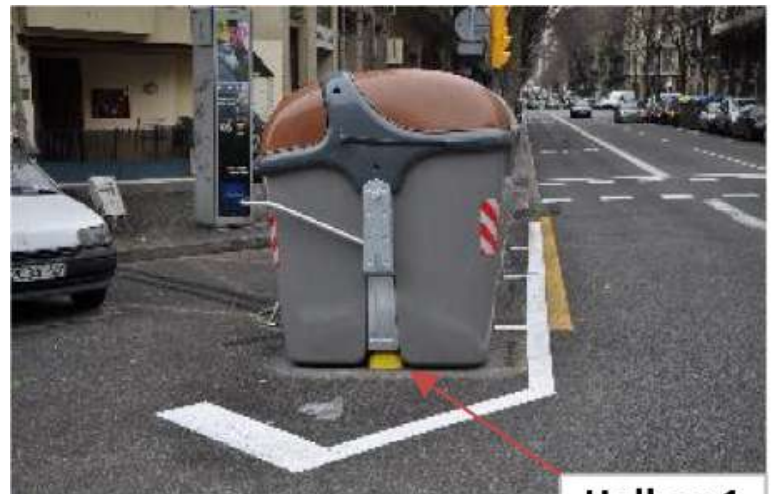

Hollow 1
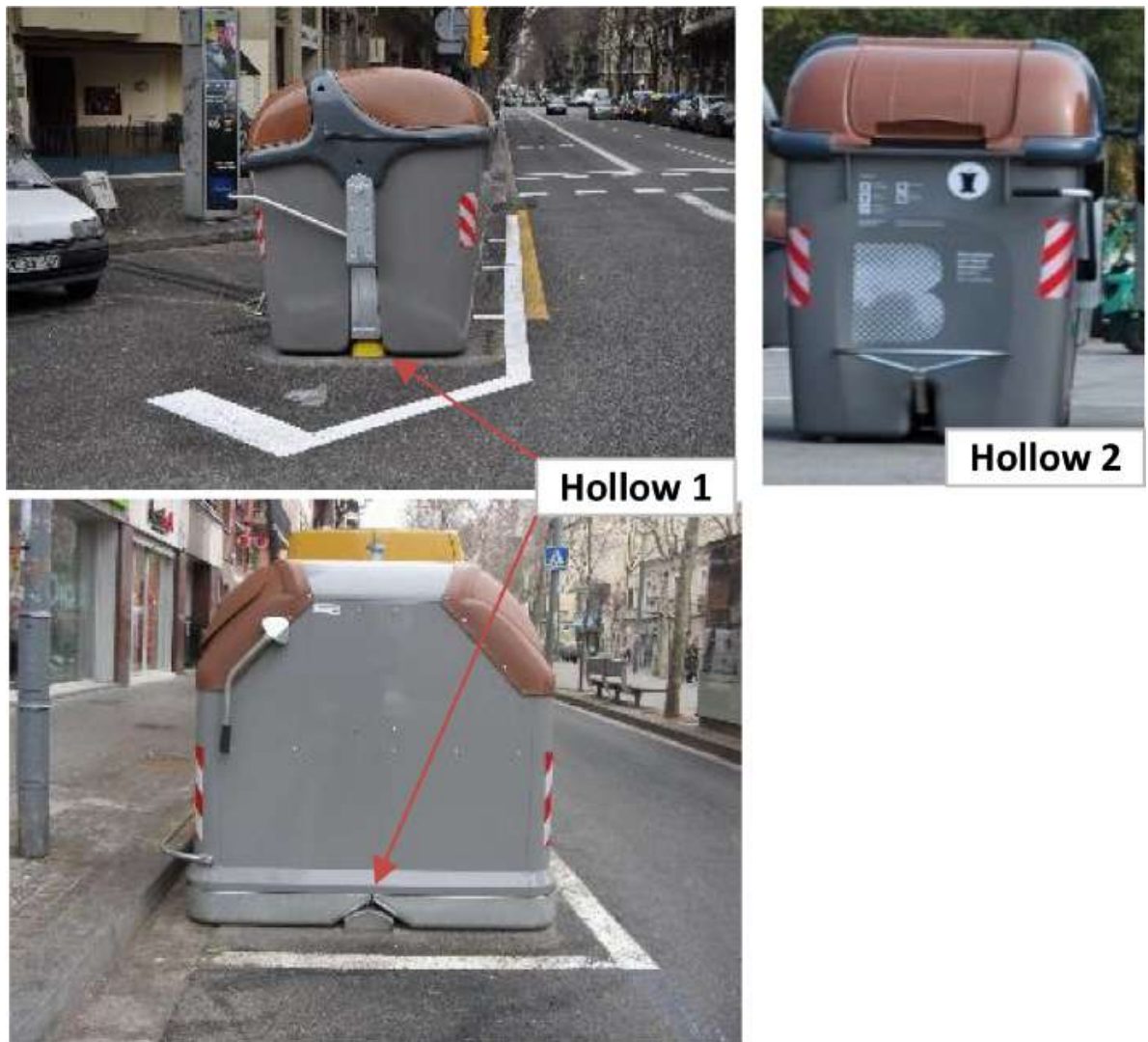
been considered by deriving a function $\left(V_{h}(y)\right)$ (Figure 9) to determine the water-filled hollows volume ( $V_{h 1}$ [lateral and bilateral] and $V_{h 2}$ [lateral]) for both types of containers (i.e., lateral and bilateral loading). This volume will be taken off the one assumed as completely solid (3); consequently, the displaced volume will be obtained based on the expression (4). Once the water depth reaches the hollows depths $\left(Y_{h \mathrm{i}}\right)$, this volume $\left(V_{h \text { imax }}\right)$ remains constant (Figure 9):

$$
V_{\text {disp }} \approx\left(L_{1} \times L_{2} \times y\right)-V_{h}(y) .
$$

On the other hand, gravitational and frictional forces will act as stabilising forces in this system of forces. The first, gravitational force $\left(F_{g}\right)$, depends on the container weight ( $W$ $\left.\left(m_{i}, p\right)\right)$, which in turn depends on their unladed weight $\left(W_{o}\right)$, the container filling $(p)$, and the type of fraction that it contains $\left(m_{i}\right)$ as described in Section 2.2. Accordingly, gravitational force can be obtained as indicated in expression (5):

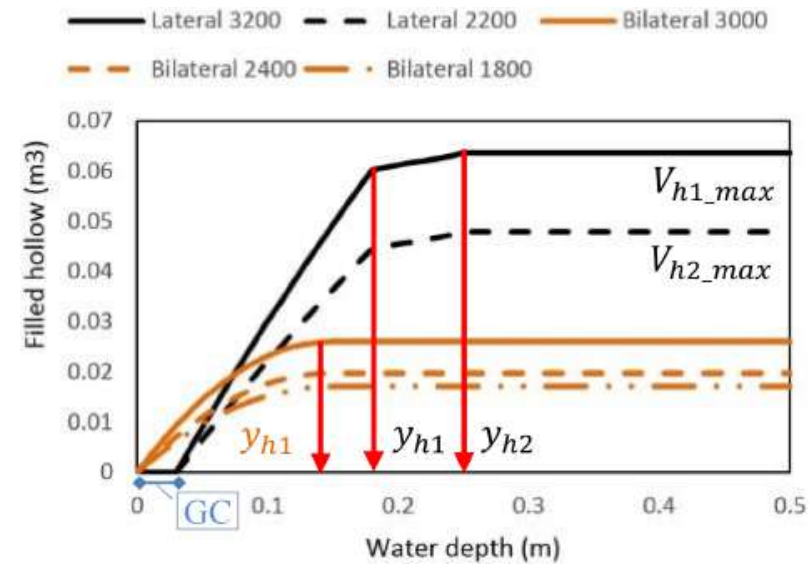

F I G U R E 9 Water filling hollows functions $\left(\mathrm{V}_{\mathrm{h}}(\mathrm{y})\right)$

$$
F_{g}=W\left(m_{i}, p\right) \times g=\left(W_{o}+m_{i} \times \frac{p}{100}\right) \times g,
$$

where $g\left(\mathrm{~m} / \mathrm{s}^{2}\right)$ is the gravitational acceleration.

However, the gravitational force stabilisation will be countered by the vertical pushing force action, to some extent, depending on the water depth. Therefore, the socalled effective weight $\left(F_{G}\right)$ may join the action of both forces $\left(F_{G}=F_{g}-F_{v}\right)$, so that the resulting $F_{G}$ will determine the vertical force stabilisation.

Previous statements only are true in case the container is located on a flat ground, thereby considering only vertical component for the normal ground reaction $\left(F_{N}\right)$. Consequently, the frictional force $\left(F_{R}\right)$ may be obtained according to the expression (6):

$$
F_{R}=\mu \times(W \times g)=\mu \times\left(W_{o}+m_{i} \times p\right) \times g,
$$

where $\mu$ is the friction coefficient between container and ground.

\section{2 | Modes of instabilities}

Different modes of instability may occur when a container is flooded (Figure 10). In case of stagnant water only buoyancy may act on the flooded container, and it will occur when the buoyancy force reaches the gravitational one. On the other hand, hydrodynamic instabilities may occur also, by either combining effects or acting isolated. Sliding instabilities will occur when the drag force exceeds the frictional one, and toppling will take place in case of container rotation from one corner of its base. In reality, both instabilities will likely occur together, when after sliding the container may be blocked by an object located on the ground and is toppled. The yellow guides placed on the ground (Figure 4) to define

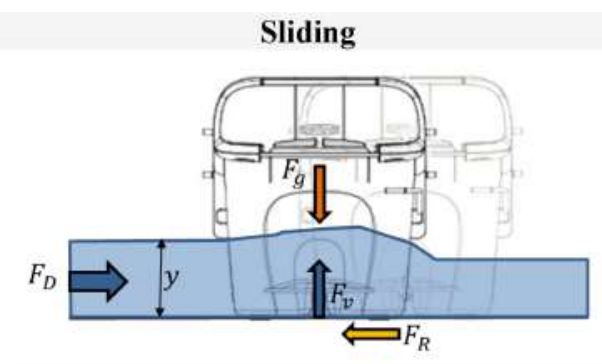

Sliding + Toppling

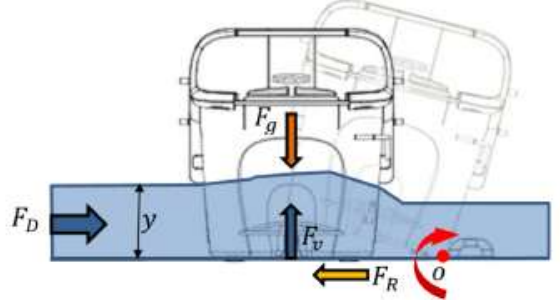

Toppling

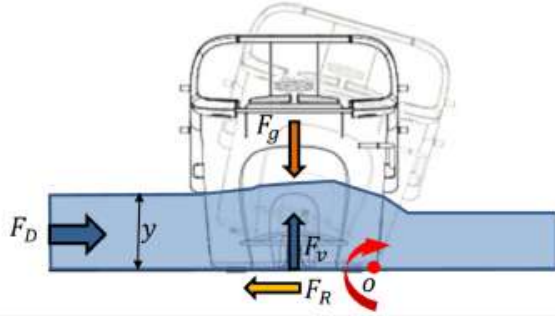

Buoyancy

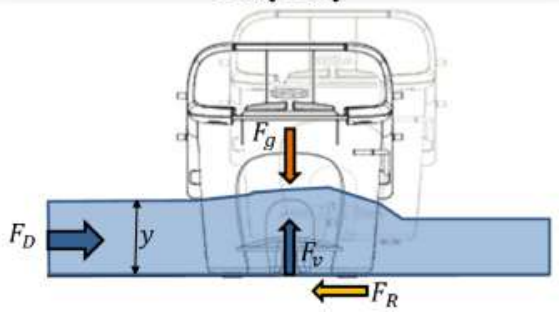

F IG URE 10 Different modes of instability for a flooded container 
the container placing area and also to fix the location of the containers themselves, could be a reason for container toppling. Regarding this yellow plastic pieces, it has to be considered that could be supportive in terms of stability in certain situations. However, the less favourable conditions have been taken into account in this study, thus the guides effect has been neglected herein.

\subsection{1 | Buoyancy}

Critical or buoyant water depth can be obtained by establishing the equilibrium condition for buoyancy (7). It can be seen also as the water depth for which the previously defined container effective weight $\left(F_{G}\right)$ becomes zero:

$$
F_{b}=F_{g}
$$

Based on this equilibrium condition, and on the buoyancy force expression (8), a critical or buoyant water depth may be derived (9).

$$
\begin{gathered}
F_{b}=\left[\left(L_{1} \cdot L_{2} \cdot y\right)-V_{h}(y)\right] \cdot \gamma_{w}, \\
y_{b}=\frac{\left(W_{o}+m_{i} \cdot p\right) \cdot g+V_{h}(y) \cdot \gamma_{w}}{L_{1} \cdot L_{2} \cdot \gamma_{w}}+G C .
\end{gathered}
$$

By applying expression (8), all critical water depths, for the different types of container with their respective characteristics (Table 2), have been calculated according to Table 3. Since the container weight depends on its filling, three filling scenarios have been taken into account: empty, half-full, and completely full.

A great variety of buoyancy depths has been obtained, ranging from $0.106 \mathrm{~m}$ (lateral loading, 3,200 L, empty, and packaging fraction) to $0.640 \mathrm{~m}$ (lateral loading, 2,200 L, full, and organic fraction).

\subsection{2 | Sliding and toppling instability}

Although the critical water depth in terms of buoyancy (i.e., hydrostatic conditions) has been obtained (Table 3), the container stability may be compromised for lower water depths when the flow velocity (i.e., hydrodynamic conditions) comes into play. As described previously, sliding, toppling or even both if it topples after being slid away, are the modes of containers instability which can arise, apart from buoyancy mode. Therefore, in this section the critical velocity functions are derived for both modes, sliding and toppling, based on establishing equilibrium condition for both modes as expressions (10)-(13) indicate, and according to the system of forces depicted in Figure 6.

\section{Equilibrium condition for sliding}

$$
\begin{gathered}
\sum F_{H}=0, \\
F_{D}=F_{R} \rightarrow \frac{1}{2} \rho_{w} v^{2} C_{d} A=\mu F_{G}=\mu\left(F_{g}-F_{v}\right),
\end{gathered}
$$

where $F_{H}$ are the different horizontal forces acting on the flooded container.

\section{Equilibrium condition for toppling}

$$
\begin{gathered}
\sum M_{0}=0, \\
M_{F_{D}}=M_{F_{G}} \rightarrow F_{D} \cdot \frac{1}{2} y=F_{G} \frac{1}{2} L_{2},
\end{gathered}
$$

where $M_{0}$ are the torques produced on the flooded container from the depicted pivoted point (O in Figure 6), $M_{F_{D}}$ is the torque due to the drag force $\left(F_{D}\right)$, and $M_{F_{G}}$ is the torque due to the effective weight $\left(F_{G}\right)$. Note that a uniform distribution of the contained fraction is assumed, so that the downwards gravitational force direction will be coincident in a same vertical with the upwards buoyancy force direction.

The threshold function (i.e., a relationship between flow velocity and water depth) for each mode of instability has been derived also for two flow directions, parallel to $L_{1}$ and $L_{2}$, which considers different areas for drag force to act on. Therefore, four threshold functions have been obtained as indicated in the expressions (13a) and 13b) and (14a) and (14b) given in Figure 11.

The two unknown parameters are the roughness coefficient $(\mu)$ and the drag coefficient $\left(C_{d}\right)$. Regarding the friction coefficient $(\mu)$ there exists a great uncertainty because it depends on where the container is placed. In this study it is supposed to be placed on the asphalt and $\mu$ for rubber against asphalt ranges from 0.25 to 0.75 according to Gerard (2006). Even so a range of values may be possible so both values have been taken into account in order to define an uncertainty between both functions, where the instability is possible depending on the real friction coefficient value $(\mu)$.

According to Isyumov (2015) the drag coefficient for square cylinders with rounded corners (i.e., the studied containers) may vary from 1.2 to 0.5 for a range of Reynolds numbers from $1.3 \times 10^{5}$ to $2.4 \times 10^{6}$. The sensitivity of the drag coefficient $\left(C_{\mathrm{d}}\right)$ has been analysed based on its effects on the stability thresholds of a lateral and 3,200 L container, $L_{2}$ flow direction, waste fraction and half-full filling 
T A B LE 3 Critical depths for the different containers and according to three scenarios: Empty, 50\% filled and full

\begin{tabular}{|c|c|c|c|c|c|c|}
\hline \multicolumn{3}{|c|}{ Type of container } & \multirow[b]{2}{*}{ Picture } & \multicolumn{3}{|c|}{ Critical depth (m) according to filling (\%) } \\
\hline Loading & Volume & Fraction & & $\mathbf{0} \%$ & $\mathbf{5 0} \%$ & $100 \%$ \\
\hline \multirow[t]{5}{*}{ Lateral } & 3,200 & Packaging & & 0.106 & 0.127 & 0.148 \\
\hline & & Paper and cardboard & & 0.106 & 0.162 & 0.212 \\
\hline & & Waste & & 0.106 & 0.194 & 0.271 \\
\hline & 2,200 & Organic & & 0.118 & 0.386 & 0.640 \\
\hline & & Glass & & 0.118 & 0.349 & 0.565 \\
\hline \multirow[t]{5}{*}{ Bilateral } & 3,000 & Packaging & & 0.139 & 0.156 & 0.173 \\
\hline & & Paper and cardboard & & 0.139 & 0.184 & 0.229 \\
\hline & & Waste & & 0.139 & 0.213 & 0.286 \\
\hline & 2,400 & Glass & & 0.155 & 0.380 & 0.605 \\
\hline & 1,800 & Organic & & 0.146 & 0.369 & 0.599 \\
\hline
\end{tabular}

scenario. In Figure 12 these thresholds have been plotted according to the formulations derived, and considering the extreme values of the drag coefficient (i.e., 1.2 and 0.5). It can be observed that sensitivity is quite high and the importance of $C_{\mathrm{d}}$ depends on the combination of the water depth and velocity that acts on the container. As expected, the higher is the drag coefficient the lower is the stability threshold, especially when it comes to sliding stability, though in a less sensitive manner on the toppling stability threshold. In
Figure 12a, the variation on the critical depths (i.e., the ones which cause the instability) for three fixed critical velocities: $1,2.5$, and $4 \mathrm{~m} / \mathrm{s}$, between the minimum sliding thresholds considering both $C_{\mathrm{d}}=0.5$ and $C_{\mathrm{d}}=1.2$, has been indicated. Although the maximum difference on the critical depths is $51 \%$ (i.e., $3.6 \mathrm{~cm}$ over $7 \mathrm{~cm}$ ) for a velocity of $4 \mathrm{~m} / \mathrm{s}$, such high velocities are not so common and velocities lower than $2.5 \mathrm{~m} / \mathrm{s}$ are more likely in urban floods. Therefore, differences lower than $32 \%$ (i.e., $3.5 \mathrm{~cm}$ over $11 \mathrm{~cm}$ ) are expected 


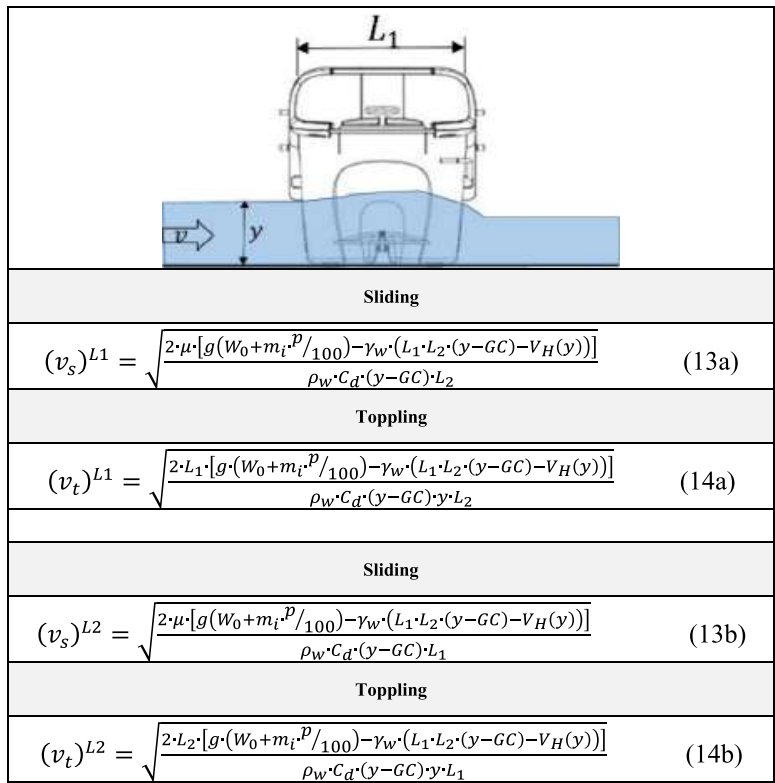

F I G U RE 11 Threshold functions for sliding and toppling instabilities according to two flow directions $\left(L_{1}\right.$ or $\left.L_{2}\right)$

to be more likely. Moreover, a similar procedure has been conducted in Figure 12b by fixing three critical depths: 10,15 , and $19 \mathrm{~cm}$, and determining the variability on the critical velocity. A percentage of $55 \%$ of increment on the critical velocities is expected in case of employing $C_{\mathrm{d}}=0.5$ instead of $C_{\mathrm{d}}=1.2$. Due to the great uncertainty in this coefficient, and acknowledging the need of experimental tests to accurately obtain the corresponding drag coefficients for each type of container, a conservative value of $C_{\mathrm{d}}=1.2$ has been adopted in later applications of this study.

Based on the adopted coefficients and on the expressions previously described, the threshold stability functions have been plotted for a lateral and 3,200 L container, $L_{2}$ flow direction, waste fraction and three filling scenarios: empty, halffull, and completely full (Figure 13). Two thresholds are plotted for sliding instability (i.e., Sliding min and Sliding max), corresponding to the minimum expected friction coefficient $(\mu=0.25)$ and the maximum expected one $(\mu=0.75)$. It is observed how the higher is the velocity the lower is the water depth for the container to become unstable. For each type of container the most restrictive flow direction (i.e., which offers the lower water depth values) has been selected. These thresholds are relevant regardless the type of flood (i.e., stormwater, riverine or coastal) that may hit the city.

\section{4 | BARCELONA CASE STUDY}

\section{1 | Barcelona hydrodynamic 1D/2D coupled model}

In the framework of the EU funded CORFU project (Russo et al., 2015), a detailed 1D/2D-coupled model, which takes into account the dual drainage concept (Djordjevic et al., 1999), was developed using Infoworks ICM version 3.0 by Innovyze (2013). ICM solves the complete 2D Saint Venant equations in a finite volume semi-implicit scheme (Godunov, 1959) with a Riemann solver (Alcrudo \& Mulet-Marti, 2005). Moreover, in order to achieve reliable simulations, experimental expressions (Gómez \& Russo, 2011) to hydraulically characterise the inlet systems were implemented.

Besides, an extended area was modelled in order to consider surface and sewer flows coming into the Raval District, which was the Spanish case study in the CORFU project (COllaborative Research on Flood resilience in Urban areas; www.corfu7.eu), from upstream catchments. The final model considered a total area of $44 \mathrm{~km}^{2}$, with 3,874 nodes, $241 \mathrm{~km}$ of total pipe length and six major storage facilities with a total capacity of $170,000 \mathrm{~m}^{3}$. A $2 \mathrm{D}$ mesh covered the whole analysed domain with 403,822 triangles.

The sewer model was calibrated and validated using records of four critical rainfall events that occurred in Barcelona in 2011. This data was recorded in 11 rain gages and 29 limnimeters. Moreover, other data collected in the postevents emergency reports (elaborated by policemen and firemen) and amateur videos recorded during the selected storm events were used to calibrate surface flow (Russo et al., 2015).

Currently, in the framework of the ongoing EU funded RESCCUE project, a more extended 1D/2D model has been developed in order to study completely the entire city of Barcelona, which is now the Spanish case study of the RESCCUE project. Not only a more extended model has been undertaken, but also all the improvements in the drainage system since 2011 have been incorporated within the earlier CORFU model.

\section{2 | Historical real stormwater flood in Barcelona (July 30, 2011)}

On July 30, 2011 a heavy rainfall event occurred which caused a major flood in Barcelona. The cumulative rainfall was $30.4 \mathrm{~mm}$ in $1 \mathrm{hr}$, the maximum rainfall intensity in $20 \mathrm{~min}$ was $105.9 \mathrm{~mm} / \mathrm{h}$ (corresponding to a return period of 8 years approximately), and a maximum rainfall intensity in $5 \mathrm{~min}$ was $140.4 \mathrm{~mm} / \mathrm{h}$ (corresponding to a return period of 2 years approximately). This rainfall event was the one employed to validate the CORFU model and its spatial distribution was taken into account by considering rainfall data recorded from 11 rain gauges across Barcelona.

The output of this model (i.e., water depths and velocities in each grid cell) has been employed in this section in order to study the potentially unstable containers within the flooded area. In this case, according to the 2D surface extent of the CORFU model, only 10,455 containers out of 23,141 (45\%) have been studied. In a way, the flood (i.e., CORFU model output) caused 
(a)
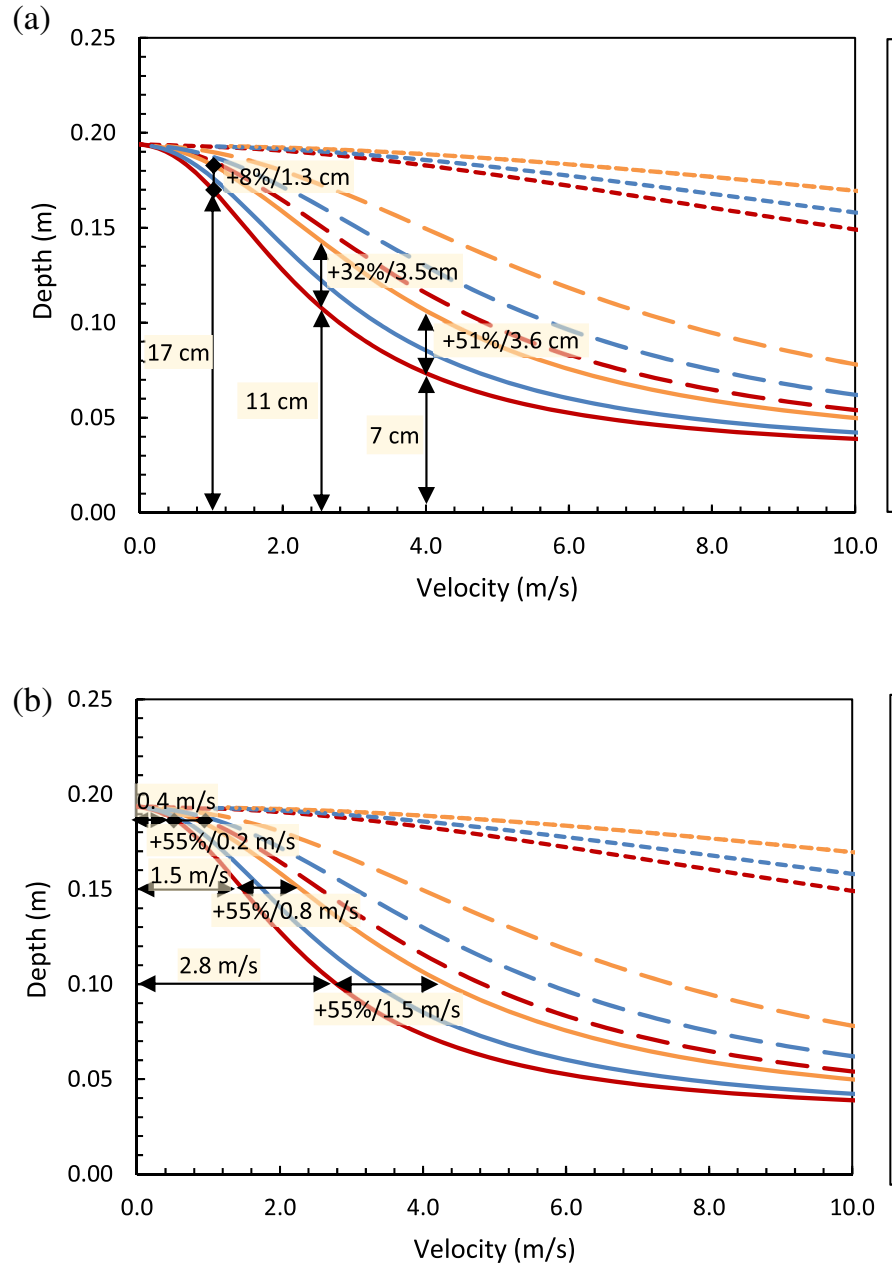

FIGURE 12 Drag coefficient sensitivity on the sliding and toppling stability thresholds (min: $\mu=0.25$ and max: $\mu=0.75$ ) for a lateral and $3,200 \mathrm{~L}$

container, $L_{2}$ flow direction, waste fraction and $50 \%$ filled container scenario
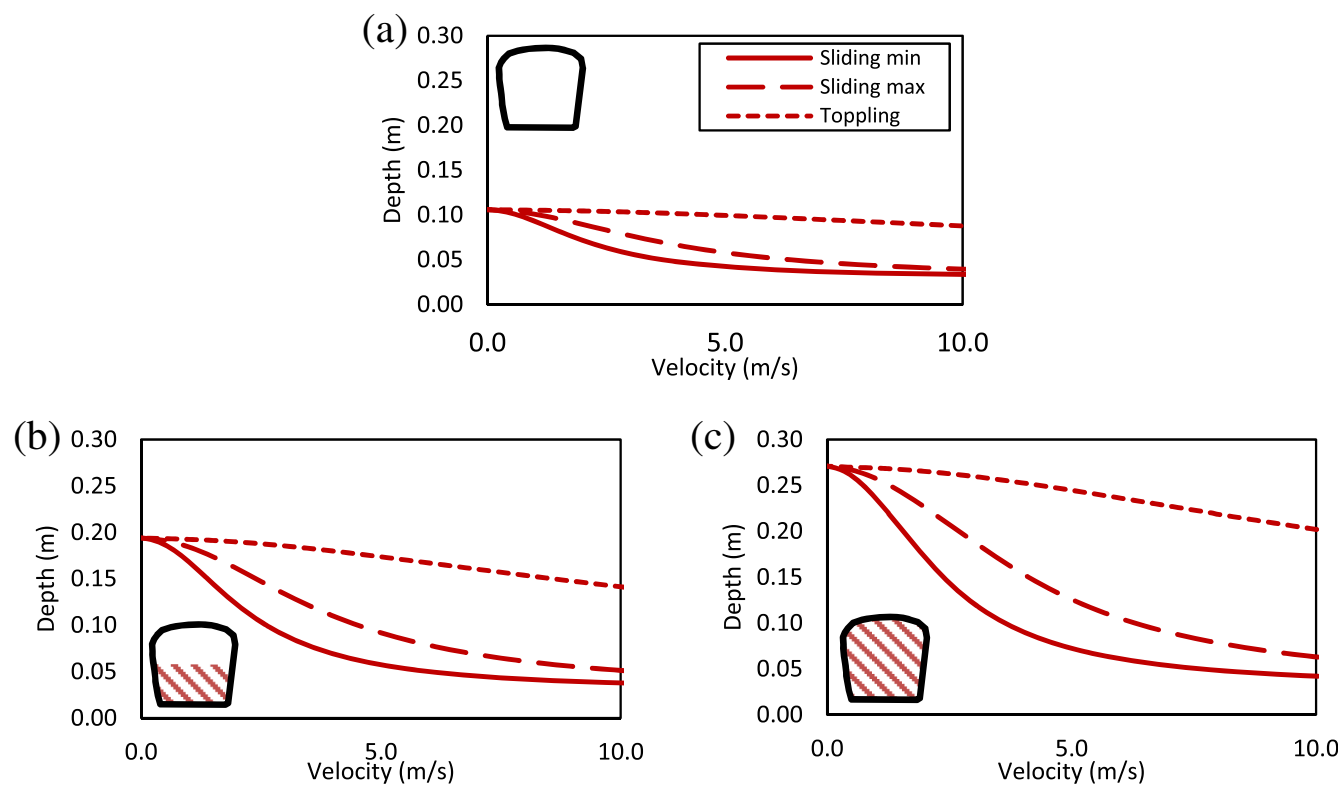

F I G URE 13 Sliding and toppling stability thresholds $\left(C_{\mathrm{d}}=1.2, \mu_{\min }=0.25\right.$, and $\left.\mu_{\max }=0.75\right)$ for a lateral and 3,200 L container, $L_{2}$ flow direction, waste fraction and (a) empty container scenario, (b) 50\% filled container scenario, and (c) full container scenario 

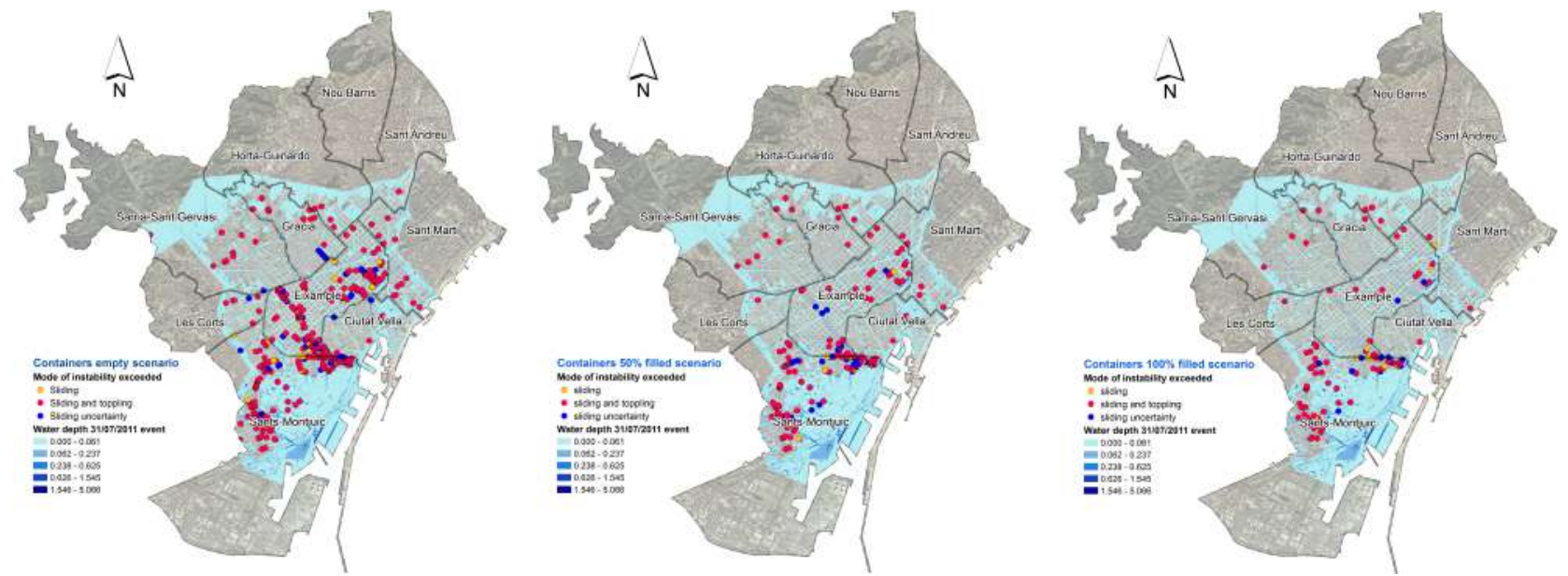

F I G U R E 14 Potentially unstable containers due to sliding and/or toppling in Barcelona for the three considered scenarios (containers empty, $50 \%$ filled and full) according to July 30, 2011 event. Note: Only the empty containers scenario offers instabilities

T A B L E 4 Number of flooded containers within the CORFU model domain per districts and percentage of containers potentially unstable

\begin{tabular}{|c|c|c|c|c|c|c|}
\hline \multirow[b]{2}{*}{ District } & \multirow[b]{2}{*}{$\begin{array}{l}\text { No. of } \\
\text { containers }\end{array}$} & \multirow[b]{2}{*}{$\begin{array}{l}\text { Total no. of studied } \\
\text { containers }\end{array}$} & \multirow[b]{2}{*}{$\begin{array}{l}\text { Total no. of flooded containers } \\
\text { within the CORFU domain }\end{array}$} & \multicolumn{3}{|c|}{$\begin{array}{l}\text { Containers potentially unstable } \\
\text { according to considered scenarios }\end{array}$} \\
\hline & & & & Empty & Half-full & $\begin{array}{l}\text { Completely } \\
\text { full }\end{array}$ \\
\hline Ciutat Vella & 1,147 & 624 & 420 & $18(4.3 \%)$ & $5(1.2 \%)$ & $3(0.7 \%)$ \\
\hline Eixample & 4,864 & 4,808 & 2,822 & $281(10.0 \%)$ & $73(2.6 \%)$ & $37(1.3 \%)$ \\
\hline Les Corts & 1,648 & 1,602 & 682 & $15(2.2 \%)$ & $2(0.3 \%)$ & $1(0.1 \%)$ \\
\hline $\begin{array}{l}\text { Sarrià-St. } \\
\text { Gervasi }\end{array}$ & 3,843 & 2,528 & 2,014 & $25(1.2 \%)$ & $8(0.4 \%)$ & $6(0.3 \%)$ \\
\hline Gràcia & 2,135 & 1,246 & 685 & $41(6.0 \%)$ & $9(1.3 \%)$ & $5(0.7 \%)$ \\
\hline St. Martí & 3,928 & 3,928 & 1,138 & $32(2.8 \%)$ & $10(0.9 \%)$ & $5(0.4 \%)$ \\
\hline
\end{tabular}

Abbreviation: CORFU, COllaborative Research on Flood resilience in Urban.

by July 30, 2011 event has been thus employed as validation of the proposed stability criteria for solid waste containers.

Three scenarios have been studied: containers empty, $50 \%$ filled and full, and the distribution of these containers potentially unstable are shown in Figure 14.

In Table 4 the number of containers studied per district is shown together with the percentage of them which are potentially unstable for the three scenarios. According to these results, it may be stated that the most vulnerable districts in terms of potentially unstable containers are Eixample and Sants-Montjuïc, considering though only in this case (i.e., CORFU model domain) less than a half of the total number of the containers were included in the modelling.

A recorded video of July 30, 2011 flood, for a specific critical spot of Ciutat Vella district is available and on it two containers are observed to be washed away (Figure 15), namely a Lateral 3,200 L Waste and a Lateral 2,200 L Organic. According to the present containers stability study, in this area one container is expected to lose its stability in case of being empty, and there is a correspondence also with the volume and fraction of one of the two containers washed away in reality. Therefore, this video provides a validation of the reliability of this study and, namely of the adequacy of the proposed stability thresholds.

\section{3 | Floods related to different design storms $(T=1,10$, and 50 years)}

Design storms of 1,10 , and 50 years return period, $155 \mathrm{~min}$ duration, and 5 min of time intervals have been developed 


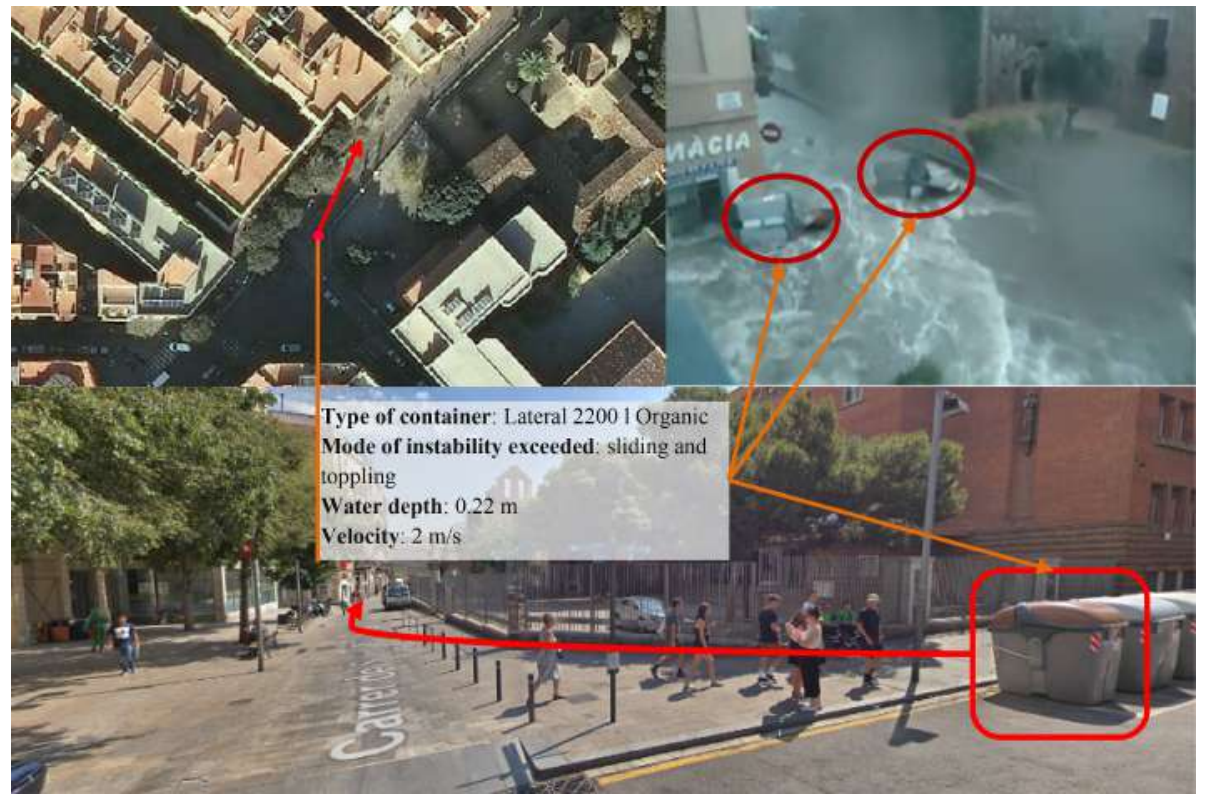

(a)

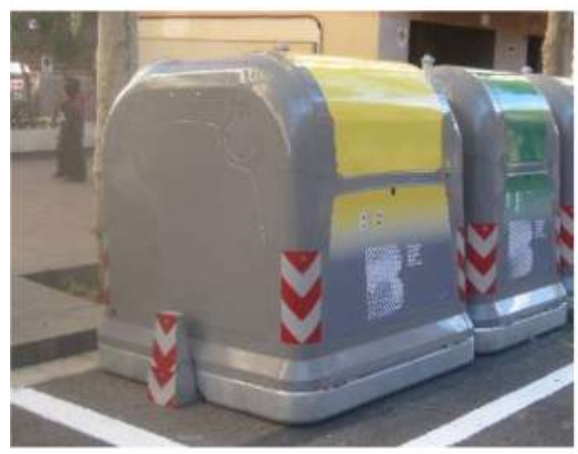

(b)

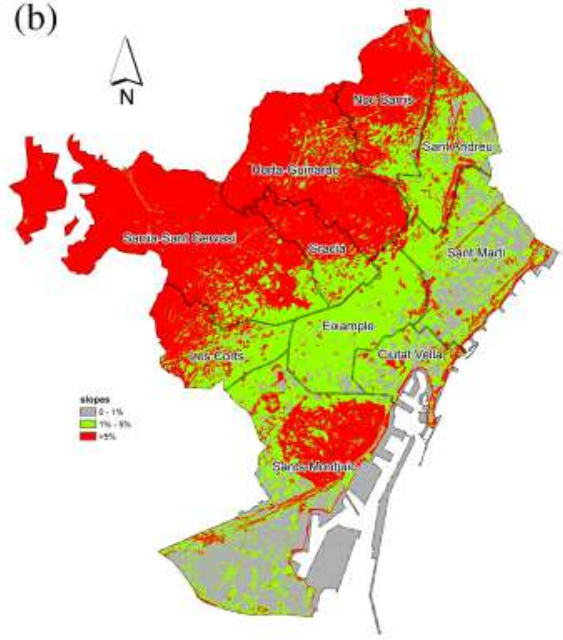

F IGURE 15 Validation of the present containers stability study based on a recorded video of the July 30, 2011 flood in Ciutat Vella district
FI GURE 16 (a) Fixation piece example, currently installed in 147 locations within Barcelona city, and (b) slopes map of Barcelona city by Barcelona Cicle de l'Aigua S.A. (BCASA), the public company managing the sewer/stormwater system of the city, through the alternating block method. The highest intensity block has been established in the minute 65 , for 1 year return period, and in the minute 130 , for 10 and 50 years return period. These have been simulated as inputs for the Barcelona hydrodynamic $1 \mathrm{D} / 2 \mathrm{D}$ coupled model used in the framework of the ongoing EU funded RESCCUE project. In this occasion, same procedure as previously described (using CORFU) has been followed, although a more extended area, which covers almost the whole Barcelona city, has been studied. It means 17,836 containers, out of 23,141 (77\%) in Barcelona, placed within the model domain and whose stability has been assessed.

Since 2016 fixation pieces (Figure 16a) started to be installed in order to ensure the stability of containers when observed that only their own weight could cause their instability in steep streets. The number of installed pieces is 147 so far, but 574 more are planned to be installed in the short term. However, these pieces may be used also to ensure stability of containers located in flat or low-slope areas (Figure 16b), which may be potentially unstable when an urban flood occurs. Therefore, these already-fixed containers are not potentially unstable due to floodwater and hence have been removed from the analysed ones.

In Figure 17 maps with the potentially unstable containers are shown, for the considered scenarios (i.e., empty, half-full, and completely full) and return periods that caused containers' instabilities (i.e., 10 and 50 years). Moreover, in Table 5 the number and percentage of containers potentially unstable is shown per district. These figures indicate the most vulnerable districts to be Eixample, St. Andreu, and Sants-Montjuïc. It has to be noted that some drainage network improvements were carried out after the actual stormwater flood event in July 30, 2011, which have been included in the complete 

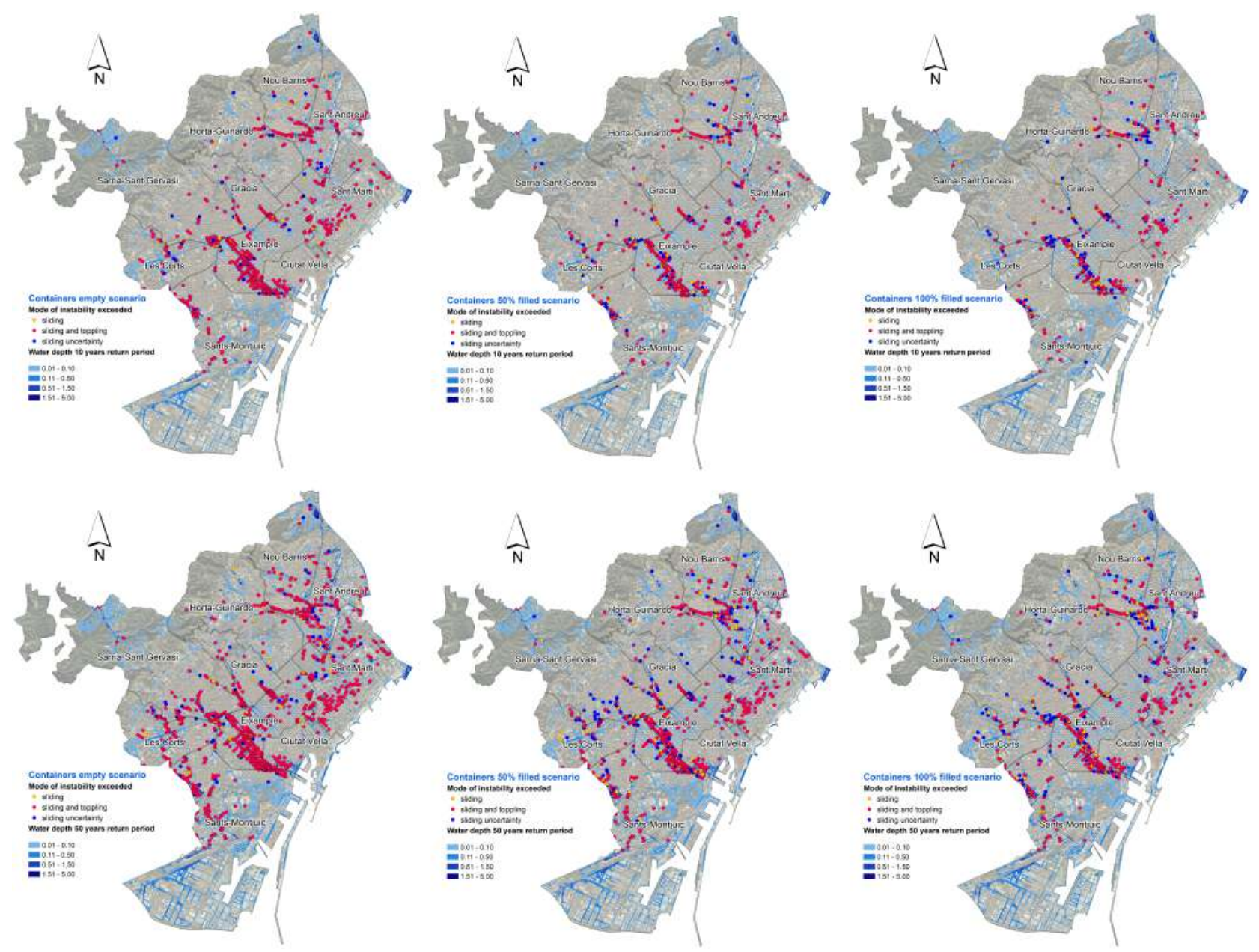

F I G U RE 17 Potentially unstable containers due to sliding and/or toppling in Barcelona for the three considered scenarios (containers empty, $50 \%$ filled and full) according to 10 and 50 years return period design storms

hydrodynamic model employed in the RESCCUE project. This fact, together with the installation of the previously mentioned fixation pieces for containers placed on steep streets, explains the current overall flood vulnerability reduction in the city, and specifically regarding containers instability.

\subsection{Adaptation measures proposed}

Based on these findings, in order to increase the resilience of waste sector against urban floods caused by a 10 years return period rainfall in Barcelona for an empty containers scenario, 1,668 fixation pieces would be necessary to be installed. It has to be noted that a couple of pieces are needed to be installed per group of containers (Figure 16a), thus two pieces have been taken into account per each group location where at least one potentially unstable container can be found. It would mean an estimated investment of 151,788 $€(91 € /$ piece). The purpose of these pieces will be to ensure the containers' stability due to floodwaters in flat areas, and due to their own weight in steep streets.

\section{5 | CONCLUSIONS}

According to the collection process for large Spanish cities (e.g., Barcelona city), before the solid waste is dumped in landfills its management starts from a regular collection of household waste municipal service which is carried out through street containers. When an urban flood occurs those containers may lose their stability, thereby allowing debris (i.e., solid waste contained) and leachate to escape from the container and contaminate floodwaters. As the waste containers stability when exposed to flooding is definitely an environmental, safety and health concern, this research has been focused on assessing how vulnerable against common urban flood these containers are in Barcelona. Moreover, some cascading effects may be caused when containers instabilities occur: traffic disruption, waste collection disruption, potential sewer blockages, and increase likelihood of cascading effects due to flooding.

The methodology proposed here is the study of the stability of the containers when exposed to urban floods, which the Barcelona City Council has distributed across the city to provide 


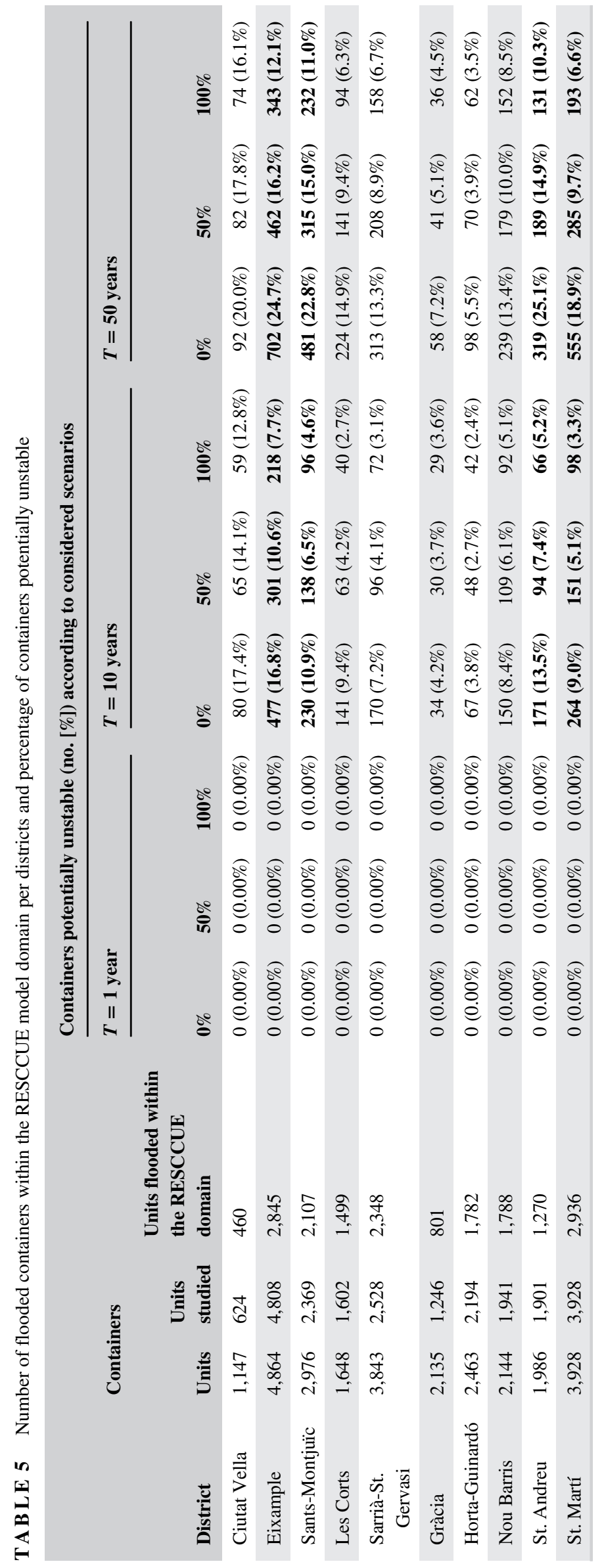


waste collection to citizens. In order to do this, three main stages were carried out:(a1) development of a 1D/2D coupled hydrodynamic model for Barcelona city; (b) derivation of stability functions for waste containers; and (c) development of a GIS map with the georeferenced containers location.

The 1D/2D hydrodynamic model covers the entire city of Barcelona, which is the Spanish case study of the RESCCUE project. The stability functions were derived based on an analysis of forces acting on a flooded container by establishing equilibrium conditions for the different modes of instability (i.e., sliding, toppling, and floating). These functions are dependent on both hydraulic variables, velocity and water depth. Moreover, the characteristics of each container (e.g., volume, dimensions, or fraction they may contain) will determine the shape of each function. The obtained stability thresholds have been employed to analyse the potential behaviour of containers against floods in Barcelona caused by historical (model validation) and design storms (i.e., 1, 10, and 50 years). The Barcelona City Council has performed a GIS-based map with the location of all types of containers across Barcelona City. This information was essential in order to study if their current location may lead to a potential instability. Therefore, the resulting outputs from the hydrodynamic model (i.e., velocities and water depth within the studied domain) were related to the containers and by applying the derived stability functions, those containers potentially unstable have been identified. Once the containers potentially unstable are identified, adaptation measures may be adopted in order to improve the resilience of waste sector against urban floods. Specifically, an estimated investment in adaptation measures (i.e., installation of fixation pieces) of $151,788 €$ would be sufficient in order to guarantee the containers stability for an empty containers scenario and urban floods related to rainfalls of 10 years return period.

The same procedure could be followed in order to analyse the flood vulnerability for containers in cities where a regular waste collection through street containers is carried out. Only new and tailored stability functions according the characteristics of the containers employed in the specific city should be derived, and resilient strategies such as the ones presented herein could be proposed.

\section{ACKNOWLEDGEMENT}

The authors thank the RESCCUE project, which is funded by the EU H2020 (Grant Agreement No. 700174), whose support is gratefully acknowledged.

\section{OR CID}

Eduardo Martínez-Gomariz (D) https://orcid.org/0000-00020189-0725

\section{REFERENCES}

Alcrudo, F., \& Mulet-Marti, J. (2005). Urban inundation models based upon the shallow water equations. Numerical and practical issues. In Proceedings of finite volumes for complex applications IV. Problems and perspectives (pp. 3-1). Paris and Oxford: Hermes Science Publishing. ISBN: 1905209487.

Butler, D., \& Davies, J. W. (2011). Urban drainage (3rd ed., p. 621p). Oxford, England: Spon Press.

Coaffee, J., \& O'Hare, P. (2008). Urban resilience and national security: The role for planning. Proceedings of the Institution of Civil Engineers: Urban Design and Planning, 161, 173-182.

Cogersa-AstUR project (n.d.). "Caracterización de los residuos domésticos mezclados de Asturias" (Mixed domestic waste characterization in Asturias (Spain)). Retrieved from http://www.cogersa.es/ metaspace/portal/14498/50093

DifferenceBetween.Com. (2011). Difference between density and bulk density. Retrieved from http://www.differencebetween.com/ difference-between-density-and-vs-bulk-density/

Djordjevic, S., Prodnovic, D., \& Maksimovic, C. (1999). An approach to simulation of dual drainage. Water Science and Technology, 39, 95-103.

Escarameia, M. (2016). Improving urban resilience to flooding: A vital role for civil engineers. Proceedings of the Institution of Civil Engineers: Urban Design and Planning, 169, 101-101.

Evans, B., Chen, A., Prior, A., Djordjević, S., Savic, D., Butler, D., ... Colclough, G. (2018). Mapping urban infrastructure interdependencies and fuzzy risks. Procedia Engineering, 212, 816-823.

Gerard, M. (2006). Tire-road friction estimation using slip-based observers (Master thesis). Department of Automatic Control, Lund University, Sweden.

Godunov, S. K. (1959). A difference scheme for numerical solution of discontinuous solution of hydrodynamic equations. Matematicheskii Sbornik, 47, 271-306, translated The Joint Publications Research Service, JPRS 7226.

Gómez, M., \& Russo, B. (2011). Methodology to estimate hydraulic efficiency of drain inlets. Proceedings of the ICE-Water Management Institution of Civil Engineers, 164, 1), 1-1), 10.

Innovyze. (2013). InfoWorks ICM (Integrated Catchment Modeling) v.2.5. User manual references.

Isyumov, N. (2015). Wind engineering terminology. In 14th international conference of wind engineering (ICWE-14). Porto Alegre, Brazil (p. 18).

Kundzewicz, Z. W., Kanae, S., Seneviratne, S. I., Handmer, J., Nicholls, N., Peduzzi, P., ... Sherstyukov, B. (2014). Flood risk and climate change: Global and regional perspectives. Hydrological Sciences Journal, 59(1), 1-28.

Lamond, J., Bhattacharya, N., \& Bloch, R. (2012). The role of solid waste management as a response to urban flood risk in developing countries, a case study analysis. In D. Proverbs, S. Mambretti, C. Brebbia, \& D. de Wrachien (Eds.), Flood recovery innovation and response (Vol. 3, pp. 193-205). Southampton, England: WIT Press.

Lhomme, S., Serre, D., Diab, Y., \& Laganier, R. (2013). Analyzing resilience of urban networks: A preliminary step towards more flood resilient cities. Natural Hazards and Earth System Sciences, 13, 221-230.

Martínez-Gomariz, E. (2016). Inundaciones Urbanas: Criterios de Peligrosidad y Evaluación del Riesgo para Peatones y Vehículos (Urban floods: Hazard Criteria and Risk assessment for 
pedestrians and vehicles). ( $\mathrm{PhD}$ thesis). Technical University of Catalonia. Barcelona, Spain (566 pp.).

Martínez-Gomariz, E., Gómez, M., \& Russo, B. (2016). Experimental study of the stability of pedestrians exposed to urban pluvial flooding. Natural Hazards, 82, 1259-1278.

Martínez-Gomariz, E., Gómez, M., Russo, B., \& Djordjević, S. (2017). A new experiments-based methodology to define the stability threshold for any vehicle exposed to flooding. Urban Water Journal, 14, 930-939.

Martínez-Gomariz, E., Gómez, M., Russo, B., \& Djordjević, S. (2018). Stability criteria for flooded vehicles: A state-of-the-art review. Journal of Flood Risk Management, 10, 817-826.

Meerow, S., Newell, J. P., \& Stults, M. (2016). Defining urban resilience: A review. Landscape and Urban Planning, 147, 38-49.

Nanía, L. S., León, A. S., \& García, M. H. (2015). Hydrologichydraulic model for simulating dual drainage and flooding in urban areas: Application to a catchment in the metropolitan area of Chicago. Journal of Hydrologic Engineering, 20, 4014071.

Patra, J. P., Kumar, R., \& Mani, P. (2016). Combined fluvial and pluvial flood inundation modelling for a project site. Procedia Technology, 24, 93-100.

Russo, B., Sunyer, D., Velasco, M., \& Djordjević, S. (2015). Analysis of extreme flooding events through a calibrated 1D/2D coupled model: The case of Barcelona (Spain). Journal of Hydroinformatics, 17, 473-491.

Sam, P. A. (2002). Are the municipal solid waste management practices causing flooding during the rainy season in Accra, Ghana, West Africa (p. 17). Lawrence, KS: University of Kansas, AERCG Department Of Geography/Environmental Studies.

Schmitt, T. G., Thomas, M., \& Ettrich, N. (2004). Analysis and modeling of flooding in urban drainage systems. Journal of Hydrology, 299, 300-311.

The Spanish Ministry of Agriculture and Fisheries, Food and Environment. (n.d.). "Biorresiduos. ¿Qué características tienen?" (Biowaste. What are their characteristics?). Retrieved from http:// www.mapama.gob.es/es/calidad-y-evaluacion-ambiental/temas/ prevencion-y-gestion-residuos/flujos/biorresiduos/BiorresiduosQue-caracteristicas-tienen.aspx
UN-HABITAT. (2010). Solid waste management in the world's cities. London, England: Earthscan (228 pp.).

United States Agency for International Development. (2012). Addressing climate change impacts on infrastructure. Preparing for change (Technical report). Global Climate Change Office, Climate Change Resilient Development project (52 pp). Washington, DC. Retrived from http://www.ccrdproject.com/ccrd-library/infrastructure

United States Agency for International Develpement. (2014). Climateresilient development: A framework for understanding and addressing climate change (Technical report). Global Climate Change Office, Climate Change Resilient Development project (40 pp). Washington, DC. Retrieved from http://www.usaid.gov/ climate/climate-resilient-development-framework

United States Agency for International Develpement. (2015). Climate resilient infrastructure services: Lessons learned (Technical report). Global climate change office, climate change resilient development project (36 pp.). Washington, DC. Retrieved from http://www.ccrdproject.com/ccrd-library/cris

Winne, S., Horrocks, L., Kent, N., Miller, K., Hoy, C., Benzie, M., \& Power, R. (2012). Increasing the climate resilience of waste infrastructure. Final report under Defra contract ERG 1102. AEA Group, Defra.

Zevenbergen, C., Cashman, A., Evelpidou, N., Pasche, E., Garvin, S., \& Ashley, R. (2010). Urban flood management (p. 1st ed.). Boca Raton, FL: CRC Press (340 pp.).

Zimmerman, R., \& Faris, C. (2010). Chapter 4: Infrastructure impacts and adaptation challenges. In New York City panel on climate change 2010 report (Vol. 1196, pp. 63-86). New York, NY: Annals of the New York Academy of Sciences.

How to cite this article: Martínez-Gomariz E, Russo B, Gómez M, Plumed A. An approach to the modelling of stability of waste containers during urban flooding. J Flood Risk Management. 2020;13 (Suppl. 1):e12558. https://doi.org/10.1111/jfr3.12558 